\title{
IMPLANTATION OF THE RAT EMBRYO : GLYCOGEN AND ALKALINE PHOSPHATASES
}

\author{
GEORGE A. CHRISTIE \\ Anatomy Department, University of Glasgow \\ (Received 12th December 1965)
}

Summary. The distribution and intensity of reaction for adenosine- $5^{\prime}-$ monophosphatase, adenosine-5'-triphosphatase, inosine-triphosphatase, thiamine-pyrophosphatase, uridine diphosphatase, $\beta$-glycerophosphatase and glucose-6-phosphatase were studied in relation to the implanting rat embryo and developing decidua at $3 \frac{1}{2}, 4 \frac{1}{2}, 5,5 \frac{1}{2}, 6,6 \frac{1}{2}, 7 \frac{1}{2}, 8 \frac{1}{2}$ and $9 \frac{1}{2}$ days of pregnancy. The distribution of glycogen was also studied from $4 \frac{1}{2}$ days onwards, using the PAS procedure in combination with diastase and/or dimedone blockade.

Glycogen was demonstrated in the stroma antimesometrial and lateral to the embryo, accumulating at 6 to $6 \frac{1}{2}$ days and gradually being compressed laterally by the expanding decidua, the lateral part of which also contained some glycogen.

All of the enzymes studied accumulated to a greater or lesser degree in the stroma initially and then in the antimesometrial decidua, where their accumulation was paralleled by a falling off of glycogen concentration.

Significant differences in distribution, particularly in the mesometrial region, were noted, adenosine-5'-monophosphatase, uridine-diphosphatase, and glucose-6-phosphatase accumulating in the cells of the glycogen wings, while the remaining enzymes did not. Adenosine-5'-triphosphatase, thiamine pyrophosphatase, and inosine-triphosphatase accumulated in the cells lining the sinusoids of this region.

Adenosine-5'-triphosphatase was the only enzyme studied to show any alteration between $3 \frac{1}{2}$ and $4 \frac{1}{2}$ days, and it is suggested that the observed antimesometrial accumulation of this enzyme may be a reflection of the oestrogen surge which occurs at this time.

An attempt is made to correlate the presence and alteration in distribution of these enzymes, and of glycogen, with what is known of their physiological functions with respect to glycogen metabolism, energy production, transport of substances across the cell membrane, and nutrition of the embryo.

\section{INTRODUCTION}

Since the classical paper of Duval (1891) on the implantation and placentation of the rat and mouse, several papers have been published dealing with the histology and histochemistry of the rat placenta (Mossman, 1937). However, 
with the exception of the work of Krehbiel (1937) and of Bridgman (1948) few histochemical studies have been made on the process of implantation in the rat, incidental to other studies, and dealing mainly with the embryo and uterine tissues from the 9th day of gestation onwards (see Everett, 1935; Alden, 1947, 1948; Bulmer \& Dickson, 1960, 1961; Dickson \& Bulmer, 1960, 1961). By this stage the process of implantation is well advanced, and major morphological alterations have already taken place in the region of the developing embryo. For this reason, and in view of the increasing interest in recent years in the endocrine control of implantation, it was felt that a re-examination of the implantation of the rat embryo, by histochemical methods (using modern techniques) was necessary. This paper is the first of a series reporting the results of such an examination, and deals with the alterations observed in the distribution and concentration of glycogen, and several specific alkaline phosphatases.

\section{MATERIAL AND METHODS}

Virgin Wistar albino rat does were mated over-night with breeding bucks, and midnight before the morning on which spermatozoa appeared in the vaginal smear was arbitrarily taken as the time of mating. At $3 \frac{1}{2}, 4 \frac{1}{2}, 5,5 \frac{1}{2}, 6,6 \frac{1}{2}, 7 \frac{1}{2}, 8 \frac{1}{2}$ and $9 \frac{1}{2}$ days of pregnancy they were killed and the uterus removed, and one horn immediately frozen on dry ice. The other horn was fixed in Bouin's fixative.

TABLE 1

ENZYMES STUDIED AND METHODS USED

\begin{tabular}{|c|c|c|}
\hline Enzyme & Method & Substrate \\
\hline $\begin{array}{l}\text { Adenosine-5' monophosphatase (AMPase) } \\
\text { Adenosine-5'-triphosphatase (ATPase) } \\
\beta \text {-Glycerophosphatase (pH } 7 \cdot 2 \text { ) } \\
\text { (control) ( } \beta \text { G-Pase) } \\
\text { Thiamine pyrophosphatase (TPPase) } \\
\text { Inosine triphosphatase (ITPase) } \\
\text { Uridine diphosphatase (UDPase) }\end{array}$ & $\begin{array}{l}\text { Novikoff } \\
\& \\
\text { Goldfischer } \\
\text { (1961) }\end{array}$ & $\begin{array}{l}\text { Adenosine-5' monophosphate } \\
\text { Adenosine-5'-triphosphate } \\
\text { Sodium } \beta \text {-glycerophosphate } \\
\text { Thiamine pyrophosphate } \\
\text { Inosine triphosphate } \\
\text { Uridine diphosphate }\end{array}$ \\
\hline $\begin{array}{l}\text { Glucose-6-phosphatase (G-6-Pase) } \\
\beta \text {-Glycerophosphatase (pH 6.7) } \\
\text { (control) }(\beta 6 \cdot 7 \text { ase) }\end{array}$ & $\begin{array}{l}\text { Wachstein } \\
\& \\
\text { Meisel } \\
\text { (1957) }\end{array}$ & $\begin{array}{l}\text { Glucose-6-phosphate } \\
\text { Sodium } \beta \text {-glycerophosphate }\end{array}$ \\
\hline
\end{tabular}

For stages earlier than $6 \frac{1}{2}$ days, the implantation sites were localized by injection of $4 \mathrm{ml}$ of Niagara Blue 2B intravenously $10 \mathrm{~min}$ before removal of the tissues. At $3 \frac{1}{2}$ and $4 \frac{1}{2}$ days no attempt was made to find the blastocysts, but uteri were sectioned both transversely and sagittally to check that no alteration in enzyme intensity occurred along their length.

Sections of implantation sites and inter-site areas were cut on a cryostat at $14 \mu$ and incubated for a variety of alkaline phosphatases as listed in Table 1 . As almost all of the substrates used can be hydrolysed to a certain extent by non-specific alkaline phosphatase, controls were incubated using $\beta$-glycerophosphate. Sections from several implantation sites at each stage were incubated individually, and for quantitative studies sections from uteri at $3 \frac{1}{2}, 4 \frac{1}{2}$, 
$5 \frac{1}{2}, 7 \frac{1}{2}$ and $9 \frac{1}{2}$ days were incubated collectively for $20 \mathrm{~min}$ at $37^{\circ} \mathrm{C}$ in one lot of medium for each enzyme studied. Time, temperature, and concentrations of substrate were strictly controlled, and to minimize diffusion of enzyme into the medium $7.5 \%$ PVP (polyvinyl pyrrolidone) was added. With the exception of the sodium $\beta$-glycerophosphate (B.D.H.), all phosphates were supplied by Sigma (London). Control sections were incubated in the medium without substrate.

Paraffin sections, at $5 \mu$, of Bouin-fixed material were stained by Masson's method or by the PAs procedure alone or with dimedone blockade (Bulmer, $1959)$ with or without diastase pre-treatment $\left(1 \%\right.$ aqueous at $\left.37^{\circ} \mathrm{C} \mathrm{for} 1 \mathrm{hr}\right)$. Complete and split series of implantation sites were stained by each method.

\section{RESULTS}

Implantation in the rat starts at 5 days with the appearance around the antimesometrial part of the uterine lumen of the primary decidual reactionfusiform basophil cells arranged parallel to the lumen. The area of reaction enlarges and spreads mesometrially, and, at $5 \frac{1}{2}$ days, the embryo makes contact

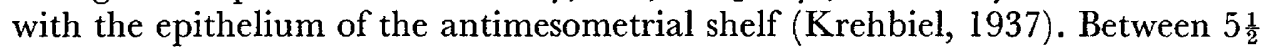
and $6 \frac{1}{2}$ days, processes of the abembryonic giant cells remove the epithelium antimesometrial to the embryo, this being associated with breakdown of the basement membrane, which commences antimesometrially and spreads towards the mesometrium; being preceded $12 \mathrm{hr}$ earlier by the removal of the epithelium. At the same time a fine reticular basement membrane develops beneath the differentiated embryonic endoderm, and the polygonal basophil cells of the secondary decidua differentiate from the primary decidua, except for a few cells immediately adjacent to the antimesometrial lumen which remain as the 'implantation zone'.

With further development the secondary decidua enlarges and compresses the stroma laterally into the so-called 'fibrinoid capsule'. The cells mesometrial and lateral to the embryo become vacuolated as they accumulate glycogen in the glycogen wings, and the breakdown of the maternal epithelial basement membrane noted above extends, in an orderly manner, from antimesometrial to mesometrial to the embryo, being replaced in relation to the yolk-sac cavity by Reichert's membrane. During this period, the cavitation of the embryo is completed, and there occurs subdivision of the egg cylinder into the ectoplacental cavity beneath the ectoplacental cone, the extra-embryonic coelom distal to it, and the amniotic cavity enclosed by the ectoderm of the inverted embryo further distally. The endoderm becomes differentiated into the typical yolk-sac endoderm mesometrial to the embryo, and a flattened layer related to the embryo itself; intra- and extra-embryonic mesoderms appear.

\section{Glycogen}

Embryo. At five days, before implantation, glycogen is found in the embryo in the form of occasional granules confined to the trophoblast. When implantation begins, however, the quantity present increases considerably until it is found in the abembryonic giant cells and the inner cell mass. This increase in quantity 
marks the start of a wave-like cycle of deposition and loss of glycogen in the trophoblast and certain structures derived therefrom-abembryonic giant cells and possibly lateral giant cells, but not in the central part of the ectoplacental cone where accumulation is seen. This cycle terminates towards the end of the period examined.

Similar cycles of deposition and loss are observed (1) in the visceral and parietal endoderms between 6 and $9 \frac{1}{2}$ days (at which time glycogen disappears temporarily from both layers), and (2) in the inner cell mass (apart from endoderm) and structures derived from it-ectoderm, and intra- and extraembryonic mesoderm-where the cycle extends from $7 \frac{1}{2}$ to $9 \frac{1}{2}$ days.

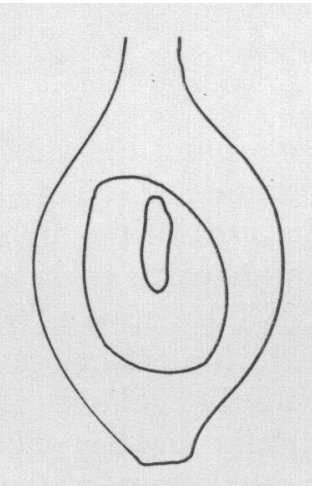

5 days

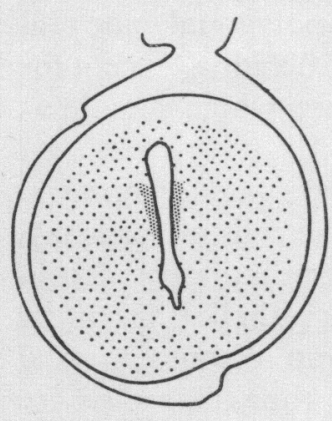

7 days

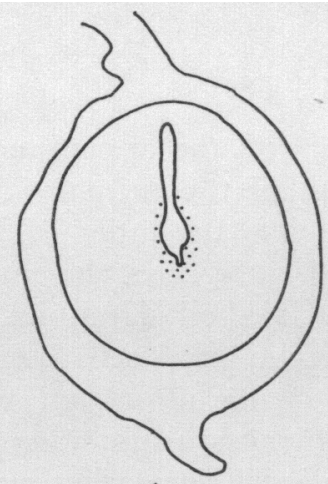

$5^{\frac{1}{2}}$ days

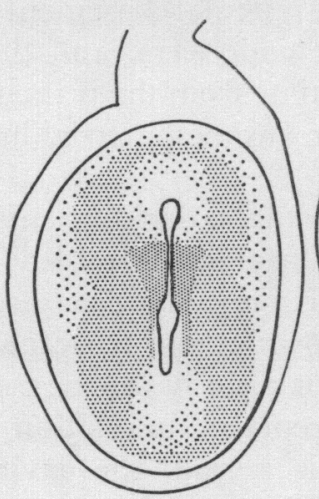

$7 \frac{1}{2}$ days

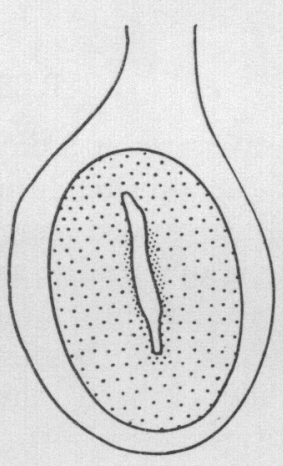

6 days

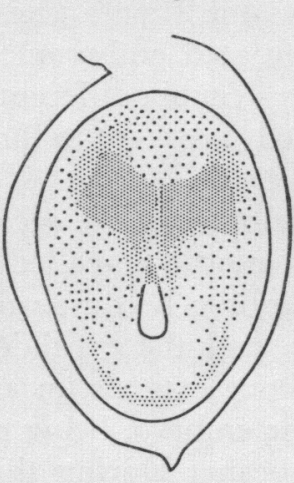

$8 \frac{1}{2}$ days

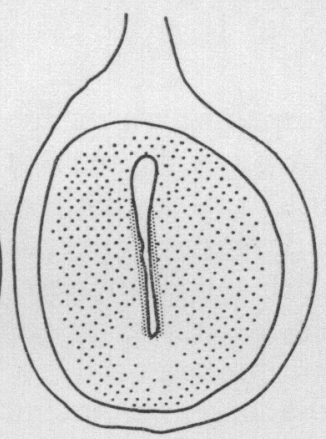

$6 \frac{1}{2}$ days

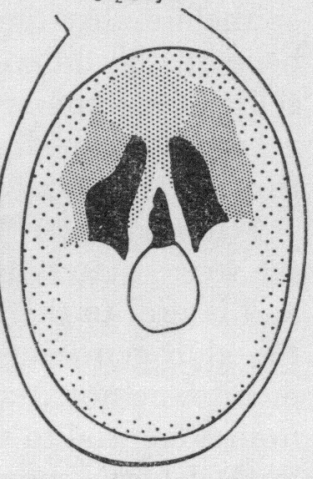

$9 \frac{1}{2}$ days

TeXT-FIG. 1. Distribution of glycogen in relation to the implanting rat embryo, as shown by the dimedone-PAs procedure. Intensity of staining is indicated by intensity of shading.

Epithelium. Throughout the period of pregnancy examined the alterations in the glycogen content mirrored those of the underlying decidua or stroma, until degeneration occurred. Some glycogen was found in the uterine secretion, which was present at all stages.

Decidua and stroma. Significant changes occur in the distribution and quantity of glycogen in the decidua and stroma cells during the period examined, and 
the dimedone blockade has allowed it to be demonstrated in sites where it has not previously been described.

At 5 days no glycogen is found in decidua or stroma, but immediately before implantation a few granules become detectable in a few cells of the primary decidua. Glycogen accumulates in this site as implantation occurs and as the transformation from primary to secondary decidua occurs, but by the 6th day an even greater quantity is found in the decidua mesometrial and lateral to the embryo, the amount tailing off as the decidua is traced antimesometrially. A few granules appear in the remainder of the stroma at this stage.

Over the next $24 \mathrm{hr}$ a considerable accumulation of glycogen in the stroma cells occurs outside the area destined to form the glycogen 'wings'. This appearance, which will persist, although in altering distribution, until the end of the stages examined, has not been described previously, possibly due to lack of sensitivity of the methods used. Initially the concentration is slightly more marked antimesometrially, and increases as the stroma is traced peripherally from immediately adjacent to the decidua. Early in the period the decidua shows the same appearance as at the 6th day with quite marked quantities mesometrial and lateral to the embryo. The 'tailing off' however is more obvious, and, while the mesometrial part with further development accumulates even more glycogen and the first traces of the glycogen wings appear, the antimesometrial decidua loses it entirely by the end of 7 days. A decrease in quantity, but not to such a degree, also occurs around the mesometrial part of the lumen.

Thus over $7 \frac{1}{2}$ and $8 \frac{1}{2}$ days, with further lateral extension of the decidua, which shows only an occasional cell containing glycogen, the area of positive staining in the stroma becomes condensed laterally and antimesometrially. Further accumulation occurs in the glycogen wings, and mesometrial to the embryo, but lateral to the embryo the staining decreases and is lost altogether. The laterally condensed capsule of positively staining stroma is separated from the glycogen wings by areas of slightly less intense reaction radiating out from its ends, and from the decidua by an area of low intensity (Text-fig. 1). Concurrent with the accumulation of glycogen in the wings, there is an increase around the residual uterine lumen mesometrially, a process which will continue until the end of the stages examined.

Over the rest of this period extension of the negative decidua laterally leads to further compression of the stroma into the area of the so-called fibrinoid capsule, which reacts intensely for glycogen at 9 days, but has become completely negative by $9 \frac{1}{2}$ days. Accumulation of glycogen also occurs in the glycogen wings until by $9 \frac{1}{2}$ days they form, in sections, an almost solid block of bright red. Apart from the glycogen around the residual uterine lumen noted above, the remainder of the decidua and stroma is negative by $9 \frac{1}{2}$ days.

Muscle layers. Little change occurs in the glycogen content of the muscle layers of the uterus over the period of pregnancy examined, which remains moderately positive throughout.

Intersites. The only site in which glycogen was observed over the whole of the period was the muscle layer, and here the concentration remained at the limits of histochemical identification. 
Non-specific alkaline phosphatase

This enzyme is known not to be particularly active towards $\beta$-glycerophosphate at $\mathrm{pH} 7 \cdot 2$ (Pearse, 1960), but some activity is observed over $3 \frac{1}{2}$ to $4 \frac{1}{2}$ days in the epithelium lining the uterine lumen and glands, traces of it in the adjacent stroma and quite a marked positive reaction in endothelium. More intense staining is seen at 5 days in the primary decidua, which increases with the increase in size of the decidua at $5 \frac{1}{2}$ days. However, at 6 days almost the whole of the stroma including the decidua becomes quite markedly positive, particularly antimesometrially. Between 6 and $7 \frac{1}{2}$ days the staining in the decidua and stroma increases to its maximum and spreads to the region round the residual uterine lumen, but the implantation zone immediately outside the embryo becomes less positive. The staining in the decidua falls off as it is traced laterally to its junction with the stroma. Thereafter the reaction continues to fall off laterally to negative just internal to the muscle layers, which remain almost negative throughout the period of pregnancy examined, as do the glycogen wings. The endothelium seems to lose its staining reaction (except peripherally) at about $6 \frac{1}{2}$ days.

From $7 \frac{1}{2}$ to $9 \frac{1}{2}$ days, there is a gradual fall off in the intensity of staining, particularly antimesometrially, beginning in the centre of the decidua and spreading laterally. The mesometrial stroma and region of the 'fibrinoid capsule' are less affected. Some positive staining appears in the centre of the ectoplacental cone, but the rest of the embryo remains negative.

\section{Adenosine-5'-monophosphatase}

The distribution of this enzyme shows marked differences from that of nonspecific alkaline phosphatase.

At $3 \frac{1}{2}$ days the epithelium of glands and uterine lumen show some activity supra-nuclearly, and traces are present in the adjacent stroma. The muscle layers exhibit a moderate degree of activity which they maintain throughout. The endothelium lining the blood vessels never shows a positive reaction with this substrate, in this species.

The changes in distribution of the staining in the antimesometrial decidua (primary and secondary) parallel those observed with $\beta$-glycerophosphate, but the reaction is much more intense in a larger area of the decidua, and does not spread to the region around the residual uterine lumen. The sudden increase in stromal staining between $5 \frac{1}{2}$ and 6 days is again present, and involves the glycogen wing region. Into this, at $7 \frac{1}{2}$ days the very intense decidual staining spreads, and further increase is seen in this region between $7 \frac{1}{2}$ and $9 \frac{1}{2}$ days : a diminution in intensity of staining, as was observed with non-specific alkaline phosphatase, occurs antimesometrially, beginning at $8 \frac{1}{2}$ days. Some activity is again seen in the centre of the ecto-placental cone at $9 \frac{1}{2}$ days. The reaction of the implantation zone is less than that of the surrounding tissue throughout the period of pregnancy examined.

\section{Adenosine-5'-triphosphatase}

This enzyme alone shows definite changes between $3 \frac{1}{2}$ and $4 \frac{1}{2}$ days. At $3 \frac{1}{2}$ days it is present in the apices of the epithelial cells of the uterine lumen and glands, 
with traces in the adjacent stroma, strongly positive blood vessel endothelium, and moderately positive muscle layers and vascular smooth muscle. By $4 \frac{1}{2}$ days, however, although the remainder of the tissue shows the same reaction, the stroma in the antimesometrial region becomes more positive within a triangle whose boundaries extend antimesometrially and laterally from either side of the mid-point of the uterine lumen. With further development the stroma becomes gradually more positive, without the abrupt transition seen between $5 \frac{1}{2}$ and 6 days with AMPase and $\beta$ G-Pase. Accumulation of enzyme occurs in primary and secondary decidua where the intensity of reaction again falls off as the decidua is traced laterally. Staining occurs in the region round the residual uterine lumen, and the reaction is intermediate in intensity between that seen with AMP and $\beta \mathrm{G}-\mathrm{P}$ as substrates. The reaction of the glycogen wings is intermediate between that of the decidua, from which they are separated by a less positive area, and the mesometrial stroma. The endothelium lining the sinusoids, however, gives a very intense reaction as does that lining the peripheral blood vessels and the maternal blood vessels supplying the ectoplacental cone. No obvious falling off in intensity of staining is observed later in the period examined, but the reaction of the decidual cells lessens between a more intense region immediately surrounding the embryo centrally, and the fibrinoid capsule peripherally. Apart from some reaction in the ectoplacental cone little activity is again seen in the embryo.

\section{Inosine triphosphatase}

The distribution and alterations in the intensity of the reactions for this enzyme almost exactly paralleled those of ATPase, with one important exception. At $4 \frac{1}{2}$ days, where the concentration of ATpase is found to be most pronounced antimesometrially, the staining for ITPase is found to be more concentrated all around the uterine lumen, falling off as it is traced laterally.

\section{Thiamine pyrophosphatase}

At $3 \frac{1}{2}$ days of pregnancy, staining for this enzyme is found in the Golgi zone of the epithelial cells lining the uterine lumen and glands, to a lesser degree in the surrounding stroma, and particularly in the endothelium of the blood vessels. A moderate reaction is observed in the smooth muscle also.

Little change occurs at $4 \frac{1}{2}$ days, but the development of the decidua is accompanied by gradual accumulation of enzyme, except in the implantation zone, up to $7 \frac{1}{2}$ to $8 \frac{1}{2}$ days. The reaction in the decidua is more marked centrally, and affects the region around the residual uterine lumen, but not the glycogen wings. As it is traced laterally the reaction fades out across decidua and stroma to negative internal to the muscle layers. The mesometrial part of the stroma accumulates a moderate degree of activity and the glycogen wings less. At its maximum the activity of enzyme in the decidua is slightly less than that observed with a $\beta$ G-Pase, and unlike the latter the blood vessel endothelium remains positive. Between $7 \frac{1}{2}$ and $9 \frac{1}{2}$ days this reaction becomes very marked in the endothelium lining the sinusoids and maternal blood vessels supplying the cone and lateral to the ectoplacental cone, while that in the decidua becomes less, with the result that the blood vessels there also become more obvious. 
Several changes of interest affect the embryo over the period from $7 \frac{1}{2}$ to $9 \frac{1}{2}$ days. When the visceral endoderm differentiates staining becomes obvious in the supra-nuclear region of the cells, but the embryonic part of this endoderm flattens and the staining there ceases to be obvious. Thus, at $9 \frac{1}{2}$ days the two different types of visceral endoderm are clearly distinguished on this basis. The abembryonic giant cells also show quite a marked degree of staining with this enzyme at $9 \frac{1}{2}$ days, as does the central part of the ectoplacental cone.

\section{Uridine diphosphatase}

At $3 \frac{1}{2}$ days some activity is present in the epithelium (supra-nuclear region) of lumen and glands, with less in the adjacent stroma. The endothelium shows an intense reaction, while the muscle layers and smooth muscle walls of the blood vessels are moderately stained.

Between $4 \frac{1}{2}$ and $7 \frac{1}{2}$ days the changes are similar to those seen with AMP as substrate (apart from the blood vessel staining) but the reaction tends to spread more towards the mesometrial part of the uterine lumen.

By $8 \frac{1}{2}$ days the reaction in the decidua and glycogen wings increases to a maximum. Thereafter an abrupt fall off in intensity occurs, affecting all areas. The mesometrial blood vessels retain their reaction throughout this period, but the lining of the sinusoids in the glycogen wings loses most of its reaction. At $9 \frac{1}{2}$ days some staining is seen in the free border of the embryonic endoderm, and in the ectoplacental cone.

\section{$\beta$-Glycerophosphatase at pH 6.7 (control for glucose-6-phosphatase)}

The distribution of staining with this enzyme is the same at this $\mathrm{pH}$ as at $\mathrm{pH} 7 \cdot 2$, but the intensity is very much less. The pattern of staining is quite different from that observed with glucose-6-phosphate as substrate.

\section{Glucose-6-phosphatase}

Less reaction for this enzyme is seen than with any other of the substrates used.

Trace activity is present in the epithelium lining the uterine lumen and glands up to $4 \frac{1}{2}$ days, the rest of the section being negative. At $5 \frac{1}{2}$ days some staining becomes visible in the primary decidua, and with the appearance of the secondary decidua this becomes more intense. The reaction, which is not seen in the implantation zone, spreads towards the mesometrial region by $7 \frac{1}{2}$ days, and increases steadily in the decidua up to the end of the period examined. By $8 \frac{1}{2}$ days staining is present in the glycogen wings, greater in intensity than in the decidua, an area of lesser activity being interposed. No fall off in staining is seen in the decidua up to $9 \frac{1}{2}$ days, and that in the glycogen wings becomes more intense. No staining of blood vessels is ever seen with this substrate.

\section{Glycogen}

\section{DISCUSSION}

Krehbiel (1937) described the accumulation of glycogen in the decidua mesometrial and lateral to the embryo where it forms the glycogen wings which extend laterally and enlarge, with further development. He also stated that 
some glycogen is found transitorily in the primary decidua antimesometrial to the embryo.

In this study the dimedone blockade demonstrated very small quantities of glycogen where they have not previously been described in relation to the implanting rat embryo. Thus, although the distribution in relation to the decidua is substantially the same as that described by Krehbiel (1937), Bridgman (1948) and Wislocki \& Dempsey (1945), none of these authors describe its occurrence in the stroma in the antimesometrial region where it starts at 6 days and continues in altering distribution till 9 days. Indeed Krehbiel states categorically that 'glycogen has disappeared from the antimesometrial region' at $7 \frac{1}{2}$ days, at which time it is at a maximum. The explanation for this difference probably lies in greater sensitivity of the PAs-dimedone procedure for glycogen as compared with the older Best's carmine or silver methods. The significance of the early accumulation of glycogen in this site is not certain, but its occurrence at a period when the embryo is dependent on histiotrophic activity for its nutrition, and its gradual disappearance with enlargement of the decidua suggests that it acts as a source of nutrition for the embryo, and is broken down to glucose by the enlarging decidual cells which then transfer the glucose to the maternal decidual blood vessels which supply the implantation area (Young, 1956). Further support for this suggestion is found in the observations that decidual cells contain a glucose-6-phosphatase, which can be associated with glycogen breakdown.

The accumulation of glycogen in the wings has already been noted by previous authors, and is presumably associated with the future development, in this region, of the chorio-allantoic placenta.

In the embryo the sensitivity of the PAs-dimedone method has again allowed glycogen to be identified at an earlier stage than previously. For example, Bridgman (1948) first described the appearance of glycogen in the yolk-sac endoderm at 10 days, while it has been shown above that a cycle of accumulation and loss, both in that site and in the parietal layer, occurs over the period from 6 days to $9 \frac{1}{2}$ days, a similar cycle occurring in the trophoblast. This study confirms Bridgman's observations on the appearance of glycogen in the ectoplacental cone or Träger, early in the period examined and shows that it begins to accumulate there, particularly centrally, at about $7 \frac{1}{2}$ days.

The significance of these findings is not completely clear, but it is of interest to note that the cycle of accumulation and loss corresponds temporally in each case with a period of maximum differentiation, or of maximum growth. Thus the cycle in the yolk-sac endoderm occurs when this organ is undergoing rapid differentiation of its cells into their definitive form, and that in the inner cell mass when the extra-embryonic mesoderm is differentiating. By contrast, the presence of glycogen in the trophoblast (for as long as it persists) and giant cells throughout the period examined may be correlated with the rapid growth required due to the expansion of the embryo; its gradual accumulation in the ectoplacental cone, particularly towards the end of the period, may reflect the future role of the latter in contributing to the formation of the definitive placenta. Further evidence in favour of this association is seen in Bullough's (1952) observation that the energy supply for mitosis in developing mouse 
epidermis is derived from glycogen, glucose and its derivatives, and from the observation by Sorokin, Padykula \& Herman (1959) of a wave-like deposition of glycogen in the budding portions of the developing lung buds.

\section{Alkaline phosphatases}

Alkaline phosphatase is often associated with glycogen deposition and recently Finn \& Hinchcliffe (1964) described its distribution in relation to the implanting mouse embryo where they considered that it acted as an index of decidualization. Pritchard (1947) described the distribution of the enzyme throughout pregnancy in the rat, and its distribution in the placenta from 13 days onwards has been studied by Wislocki, Deane \& Dempsey (1946). Unfortunately, in each case, the tissues were fixed and paraffin embedded before sectioning, which treatment is known to destroy a variable amount of the enzyme present (Pearse, 1960). Also, the methods used were those for non-specific alkaline phosphatase, which is now thought to be a mixture of a number of enzymes. More recently, Padykula (1958) has studied non-specific alkaline phosphatase and adenosine-5'-triphosphatase on unfixed cryostat sections, and Padykula \& Richardson (1963) have studied glucose-6-phosphatase, but in each case their observations were confined to the chorio-allantoic placenta from 13 days onwards.

There has been considerable discussion in the recent literature regarding the specificity of the methods used above for enzymes hydrolysing the substrate under investigation (Barden \& Lazarus, 1963; Lazarus \& Barden, 1962; Allen, 1963; Freiman \& Kaplan, 1960; Wachstein, Meisel \& Niedwiedz, 1960). Certainly all of the substrates used are hydrolysed to a greater or lesser extent by non-specific alkaline phosphatase, but at the $\mathrm{pH}$ used (7.2) the activity of this enzyme is at a low level (Pearse, 1960). In this study the activity of non-specific alkaline phosphatase in the decidua was always less than that observed with any of the other substrates, and the staining pattern was different with each, with the possible exception of ATP and ITP, both of which are known (Barden \& Lazarus, 1963) to be hydrolysed in mitochondria by one enzyme. On these grounds it is felt that the methods used in this study have been specific, and allow some comparison to be made between the different enzymes at successive stages of pregnancy.

\section{Adenosine-5'-triphosphatase}

This enzyme is known to be concerned with energy production in cells, and with transport across cell membranes (Hokin \& Hokin, 1963), and it has been suggested that the transport of sugars across cell membranes may be linked to the ATP activated 'sodium pump' (Crane, 1962). Thus in the antimesometrial decidua, which is an area of rapidly growing and enlarging cells, metabolically very active, considerable quantities of ATPase accumulate up to $8 \frac{1}{2}$ days. Presumably the enzyme in this site is associated with transport of substances to the embryo, whose nutrition at this stage is purely histiotrophic, and with synthesis of materials necessary for its continued growth and survival. As regards its function in transport, it is of interest that an inverse relationship exists between the concentration of ATPase (more centrally, less peripherally) and that 
of glycogen (more peripherally, less centrally) suggesting that the enzyme is involved, in this site, in transport of glucose derived from the breakdown of glycogen (see below) to the embryo.

With decrease in importance of the antimesometrial decidua, as the ectoplacental cone becomes bathed in maternal blood, and the source of embryonic nutrition tends to shift towards the mesometrial region, the concentration of ATPase falls off slightly, although the region immediately surrounding the embryo-the zone of trophoblastic giant cells in which the maternal blood is thought (Bridgman, 1948) to circulate-remains intensely positive in reaction. However, the reaction of the lining of the maternal blood vessels supplying the ectoplacental cone becomes very intense, as does that of the sinusoids in the glycogen wing regions. The staining in this site would seem to be associated with the swollen endothelium visible on histological preparations, endovascular plasmodium as described by Bridgman not yet having developed; it is probably associated again with transport across cells either of glycogen precursors into the glycogen cells, or of glucose derived from them into the maternal blood for the nutrition of the embryo.

The changes seen in the concentration of ATPase between $3 \frac{1}{2}$ and $4 \frac{1}{2}$ days are of interest. This is the period of the oestrogen surge (Mayer, 1963) which is followed, at 4 days and $16 \mathrm{hr}$ in our strain of rats, by the appearance of the positive 'blue' reaction of Psychoyos (1965) which he considered to be indicative of an increase in capillary permeability. Certainly the accumulation of water in rat uterus is known (Boettiger, 1946) to be associated with oestrogen, and transport of water across cell membranes is associated with ATPase. Thus the primary action of the oestrogen surge may be to cause an increase in ATPase activity in the capillaries and stroma of the uterus, thereby producing an increase in their permeability, which leads to the 'blue reaction'. The localization of the increase in enzyme activity to the antimesometrial region may be a factor in bringing about the preferential implantation of the embryo in that part of the uterus.

\section{Adenosine-5'-monophosphatase, glucose-6-phosphatase, uridine diphosphatase, inosine triphosphatase}

Recently it has been suggested (Stetten \& Stetten, 1960) that glycogen synthesis in most animals takes place through the action of UDPG-glycogen transferase and branching enzyme, while its breakdown is mediated by phosphorylase to glucose-1-phosphate. These enzymes have been studied in induced deciduomata by Bo, Smith \& Colborn (1964), who considered that glycogen synthesis in this site occurs from glucose-1-phosphate by phosphorylase. However, their results were very variable, and no definite conclusions can be drawn from them. As the enzymes studied act on substrates important in the synthesis and breakdown of glycogen, it is of interest to seek some correspondence between their distribution and alterations, and those of glycogen in the decidua and stroma.

The reactions involved in glycogen synthesis and breakdown, and the stages at which the enzymes studied enter into their sequence are indicated in Table 2.

The importance, at first of the decidua and then of the glycogen wing region, in the production of glucose, presumably for the nutrition of the embryo, can be seen from the changes in glucose-6-phosphatase. This enzyme builds up initially 


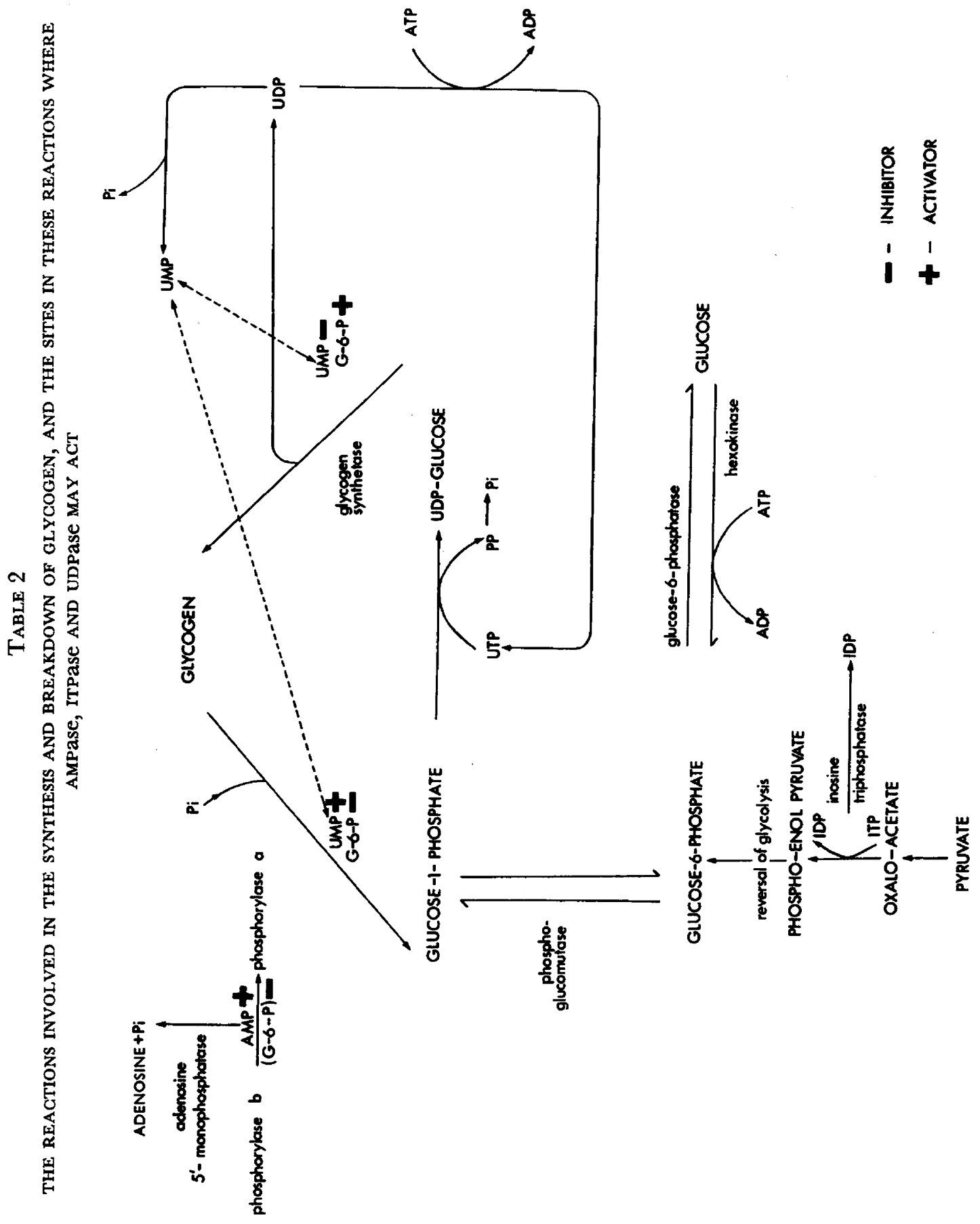


in the antimesometrial decidua, and here some correlation exists between the changes of concentration of glycogen observed and of the enzyme. The glycogen increases to a maximum antimesometrially at $7 \frac{1}{2}$ days, falling off thereafter to none at $9 \frac{1}{2}$ days, disappearing first from the centre of the region, while the enzyme builds up steadily over the period from about $6 \frac{1}{2}$ days onwards, starting in the centre. Thus the final step in the disappearance of glycogen from this site may well be due, in part at least, to this enzyme. Build-up of glucose-6phosphate is inhibitory to phosphorylase (Fridland \& Nigam, 1965) possibly by a direct action on the enzyme system, possibly by its inhibitory action on the activating effect of adenosine-5'-monophosphate (Morgan \& Parmeggiani, 1964) in the conversion of phosphorylase-b to phosphorylase-a. For this reason also the build up of glucose-6-phosphatase, by removing this substance, would again aid in the breakdown of glycogen. Once the glucose is produced it could then be transferred to the blood vessels of the region whose direction of flow is towards the embryo whose nutrition would thus be assured.

The changes seen in the other enzymes studied in the antimesometrial decidua, with the possible exception of ITPase which may be the same enzyme as hydrolyses ATP, are more difficult to correlate with the alterations in glycogen content. As can be seen from Table 2, UMP, which would be produced by the action of UDPase, is inhibitory to glycogen synthetase, and activating to phosphorylase (Fridland \& Nigam, 1965) and the destruction of uDP by the enzyme would make less available for re-phosphorylation and re-circulation in the UDPG-glycogen synthesis system. AMPase, on the other hand, by destruction of AMP would remove its activating action on phosphorylase (Morgan \& Parmeggiani, 1964). Thus the two enzymes would seem to be competitive in action, with respect to the metabolism of glycogen. However, correlation of these results may be possible if the control of synthesis and breakdown of glycogen in this site is mainly mediated by alterations in the level of uDPase, which builds up to a maximum in the centre of the decidua at $8 \frac{1}{2}$ days, starting at $6 \frac{1}{2}$ days, when the accumulation of glycogen is quite well advanced. Accompanying the build-up of enzyme, the glycogen level begins to fall off, starting in the centre of the decidua, until, by $8 \frac{1}{2}$ days, it has almost all disappeared and the enzyme level is at a maximum. Thereafter the uDPase level falls off, presumably as there is no further glycogen to be acted upon. AMPase in this site would serve the function of destroying AMP after it had activated the phosphorylase required for the breakdown of the glycogen, and also by limiting the amount of phosphorylase available for breakdown, could act as a brake on the speed with which the glycogen is removed.

By $9 \frac{1}{2}$ days the important source of foodstuffs to the embryo shifts to the mesometrial region, and a reflection of this is seen in the build up of glucose-6phosphatase in the glycogen wings, where it is presumably associated with the breakdown of glycogen and its release into the blood stream. While the blood vessels in this region are generally considered to be venous channels draining the placental site, rather than supplying blood to it (Young, 1956), it seems likely that the flow in them will be very variable in direction due to uterine contractions, and that the glucose released into them will reach the embryo.

If the control of the glycogen level in antimesometrial decidua is through 
the action of uDpase, the concentration of glycogen would be expected to fall rather abruptly to $8 \frac{1}{2}$ days and thereafter rise, thus exhibiting an inverse ratio to the concentration of enzyme. This does not occur (Plates 3 and 4 ) since the quantity of glycogen increases rapidly in this region from $7 \frac{1}{2}$ to $9 \frac{1}{2}$ days. A possible explanation of this apparently anomalous situation, however, can be seen in the abrupt rise in AMPase concentration, starting at $7 \frac{1}{2}$ days and continuing to increase over the entire period. This enzyme, by applying a firm brake on the quantity of phosphorylase available, could counteract the increase in uDPase from $7 \frac{1}{2}$ to $8 \frac{1}{2}$ days, and allow glycogen accumulation to occur. After $8 \frac{1}{2}$ days, when the concentration of uDPase falls off, the conditions for glycogen synthesis would become favourable, and the rapid increase in glycogen which occurs at this time would be expected.

\section{Thiamine pyrophosphatase}

This enzyme, and possibly also udpase (Lazarus \& Barden, 1962) is thought to be localized to the Golgi apparatus of the cell (Novikoff \& Goldfischer, 1961), although more recently (Penney \& Barrnett, 1965) its presence there has been denied, and it has been stated that it appears in the intercellular space where it is due to a non-specific poly-phosphatase.

In this study, localization to what would seem to be the Golgi region of the cell has been noticed in two sites, the uterine epithelium around the lumen and in glands where it is presumably associated with secretion into the lumen, and the embryonic endoderm where, unless it be concerned with secretion into the cavity of the yolk sac, its function is less certain.

The position of the TPPase seen in the cells of the decidua is less certain. The histochemical picture is different from that seen with any of the other substrates examined, although the distribution and alterations in this site are similar, and the concentration is generally less. Although this is by no means conclusive it would suggest that the localization is again to the Golgi apparatus, where it can only be assumed that it is concerned with the secretion of substances (possibly protein in view of the accumulation of RNA in these cells) into the blood stream to supply the embryo. Certainly if the localization was to the intercellular spaces, as has been suggested for the rat adrenal (Penney \& Barrnett, 1965), a similar picture would be expected to be present when $\beta$-glycerophosphate was used as substrate, but this is not so.

Yet another site in which this enzyme may be associated with the Golgi apparatus is in the endothelium lining the sinusoids of the glycogen wings, where staining becomes very prominent between $7 \frac{1}{2}$ and $9 \frac{1}{2}$ days, and where secretion into the blood stream to supply nutrition to the embryo is presumably occurring. The increase in prominence in this site may be associated with thickening of the sinusoid lining, due to swelling of the endothelium which begins at $7 \frac{1}{2}$ days, and is not to be confused with the development of endovascular plasmodium, which occurs later and chiefly affects the maternal blood vessels in the mesometrial region supplying the ectoplacental cone.

The significance of the appearance of this enzyme in the ectoplacental cone is not certain but here again it may be associated with the Golgi apparatus and secretion of substances to the embryo. 


\section{REFERENCES}

Alden, R. H. (1947) Implantation of the rat egg. II. Alteration in osmiophilic epithelial lipids of the rat uterus under normal and experimental conditions. Anat. Rec. 97, 1.

ALDEN, R. H. (1948) Implantation of the rat egg. III. Origin and development of the primary trophoblast giant cells. Am. F. Anat. 82, 143.

ALLEN, J. M. (1963) The properties of Golgi-associated nucleoside diphosphatase and thiamine pyrophosphatase. I. Cytochemical analysis. 7. Histochem. Cytochem. 11, 529.

BARDEN, H. \& LAZARUS, S. S. (1963) Histochemical characterisation of adenosine triphosphate dephosphorylating enzymes in rabbit pancreas. F. Histochem. Cytochem. 11, 578.

Bo, W. J., Smith, M. S. \& Colberg, G. (1964) Histochemical studies on phosphorylase and uridine diphosphate glucose-glycogen transferase in decidual cells of the rat. Anat. Rec. 150, 173.

BOETiger, E. G. (1946) Changes in the glycogen and water content of the rat uterus. F. cell. comp. Physiol. 27, 9.

Bridgman, J. (1948) A morphological study of the development of the placenta of the rat. 7. Morph. 83, 61 .

Bullough, W. S. (1952) The energy relations of mitotic activity. Biol. Rev. 27, 133.

BuLmer, D. (1959) Dimedone as an aldehyde blocking reagent to facilitate the histochemical demonstration of glycogen. Stain Tech. 34, 95.

Bulmer, D. \& Dickson, A. D. (1960) Observations on carbohydrate materials in the rat placenta. $\mathcal{F}$. Anat. 94, 45.

Bulmer, D. \& Dickson, A. D. (1961) The fibrinoid capsule of the rat placenta and the disappearance of the decidua. $\mathcal{7}$. Anat. 95, 300 .

Crane, R. K. (1962) Hypothesis for mechanism of intestinal active transport of sugars. Fedn proc. Fedn Am. Socs exp. Bial. 21, 891.

Dickson, A. D. \& Bulmer, D. (1960) Observations on the placental giant cells of the rat. 7. Anat. 94, 418.

Dickson, A. D. \& Bulmer, D. (1961) Observations on the origin of metrial gland cells in the rat placenta. f. Anat. 95, 262.

Duval, M. (1891) Le placenta des rongeurs. III. Le placenta de la souris et du rat. F. Anat. Physiol., Paris, 27, 24; 344; 515.

Everett, J. W. (1935) Morphological and physiological studies of the placenta in the albino rat. $\mathcal{J}$. exp. Zool. 70, 243.

Finn, C. \& Hinchcliffe, J. R. (1964) Reaction of the mouse uterus during implantation and deciduoma formation as demonstrated by changes in the distribution of alkaline phosphatase. 7 . Reprod. Fert. 8, 331 .

Freiman, D. G. \& Kaplan, N. (1960) Studies on histochemical differentiation of enzymes hydrolysing adenosine-5'-triphosphate. 7. Histochem. Cytochem. 8, 159.

FridLANd, A. \& NigAM, V. N. (1965) Effects of glucose-6-phosphate, 2-deoxy-glucose-6-phosphate, and uridine monophosphate on phosphorylase and uridine diphosphate glucose-glycogen synthetase in pigeon liver. Archs Biochem. Biophys. 111, 477.

Hokin, L. E. \& Hokin, M. R. (1963) Biological transport. A. Rev. Biochem. 32, 553.

KREHBIEL, R. H. (1937) Cytological studies of the decidual reaction in the rat during early pregnancy and in the production of deciduomata. Physiol. Zool. 10, 212.

Lazarus, S. S. \& Barden, H. (1962) Demonstration of nucleoside diphosphatase activity in the Golgi apparatus at alkaline pH. 7. Histochem. Cytochem. 10, 368.

Mayer, G. (1963) Delayed nidation in rats. Delayed Implantation, pp. 213-231. Ed. A. C. Enders. University of Chicago Press, Chicago, Illinois.

Morgan, H. E. \& Parmeggiani, A. (1964) Regulation of glycogenolysis by phosphorylase in muscle. 7. biol. Chem. 239, 2440.

Mossman, H. W. (1937) Comparative morphogenesis of the foetal membranes and accessory uterine structures. Carnegie Inst. Wash. Publ. 479. Cont. Embryol. 158, 129.

Novikoff, A. B. \& Goldfischer, S. (1961) Nucleoside diphosphatase activity in the Golgi apparatus, and its usefulness in cytological studies. Proc. natn. Acad. Sci. U.S.A. 47, 802.

Padykula, H. A. (1958) A histochemical and quantitative study of enzymes of the rat placenta. $\mathcal{F}$. Anat. 92, 118.

Padykula, H. A. \& Richardson, D. (1963) A correlated histochemical and biochemical study of glycogen storage in the rat placenta. Am. F. Anat. 122, 215.

Pearse, A. G. E. (1960) Histochemistry, theoretical and applied. Churchill, London.

Penney, D. P. \& Barrnetr, R. J. (1965) The fine structural localization and selective inhibition of nucleosidephosphatase in the rat adrenal cortex. Anat. Rec. 152, 265.

PrItchard, J. J. (1947) The distribution of alkaline phosphatases in the pregnant uterus of the rat. f. Anat. 81, 352. 
Psychoyos, A. (1965) Controle de la nidation chez les mammifères. Archs Anat. microsc. 54, 85.

Sorokin, S., PADYKula, H. A. \& HERMan, E. (1959) Comparative histochemical patterns in developing mammalian lungs. Devl Biol. 1, 125.

Stetten, D. \& Stetren, M. (1960) Glycogen metabolism. Physiol. Rev. 40, 505.

WACHstein, M. \& MEISEL, E. (1957) Histochemistry of hepatic phosphatases at a physiological pH. Am. F. clin. Path. 27, 13.

Wachstein, M., Meisel, E. \& Niedwiedz, A. (1960) The visualization of mitochondrial adenosine triphosphatase by a lead-ATP method at $\mathrm{pH} 7 \cdot 2.7$. Histochem. Cytochem. 8, 387.

Wislocki, G. B. \& Dempsey, E. W. (1945) Histochemical reactions of the endometrium in pregnancy. Am. F. Anat. 77, 365.

Wislocki, G. B., Deane, H. W. \& Dempsey, E. W. (1946) The histochemistry of the rodent's placenta. Am. F. Anat. 78, 281.

Young, A. (1956) The vascular architecture of the rat uterus during pregnancy. Trans. R. Soc. Edinb. 63,167 .

\section{EXPLANATION OF PLATES}

In Plates 1 to 4 the distribution and intensity of the staining reactions for the various substances examined are illustrated, at typical stages before, during or after implantation. The arrangement in each plate is similar, and reading from left to right, is:

Top row: Ampase, ATPase, $\beta$ glycerophosphatase at $\mathrm{pH} 7.2$

Middle row: Histology (Masson), ITPase, G-6-Pase.

Bottom row: Glycogen (PAS-dimedone procedure), TPPase, uDPase.

Plate 1. Transverse sections through the uterus of a $4 \frac{1}{2}$-day pregnant rat.

Plate 2. Transverse sections through the implantation site of a $5 \frac{1}{2}$-day pregnant rat uterus, showing the reactions of the primary decidua.

Plate 3. Transverse sections through the implantation site of a $7 \frac{1}{2}$-day pregnant rat uterus, showing the reactions in the secondary decidua, and developing glycogen wings.

Plate 4. Transverse sections through the implantation site of a $9 \frac{1}{2}$-day pregnant rat uterus, showing the fall off in reaction in the secondary decidua, and the increase, in most cases, in the glycogen wings. The TPPase reactions in the visceral yolk sac endoderm of the embryo are indicated (X). 

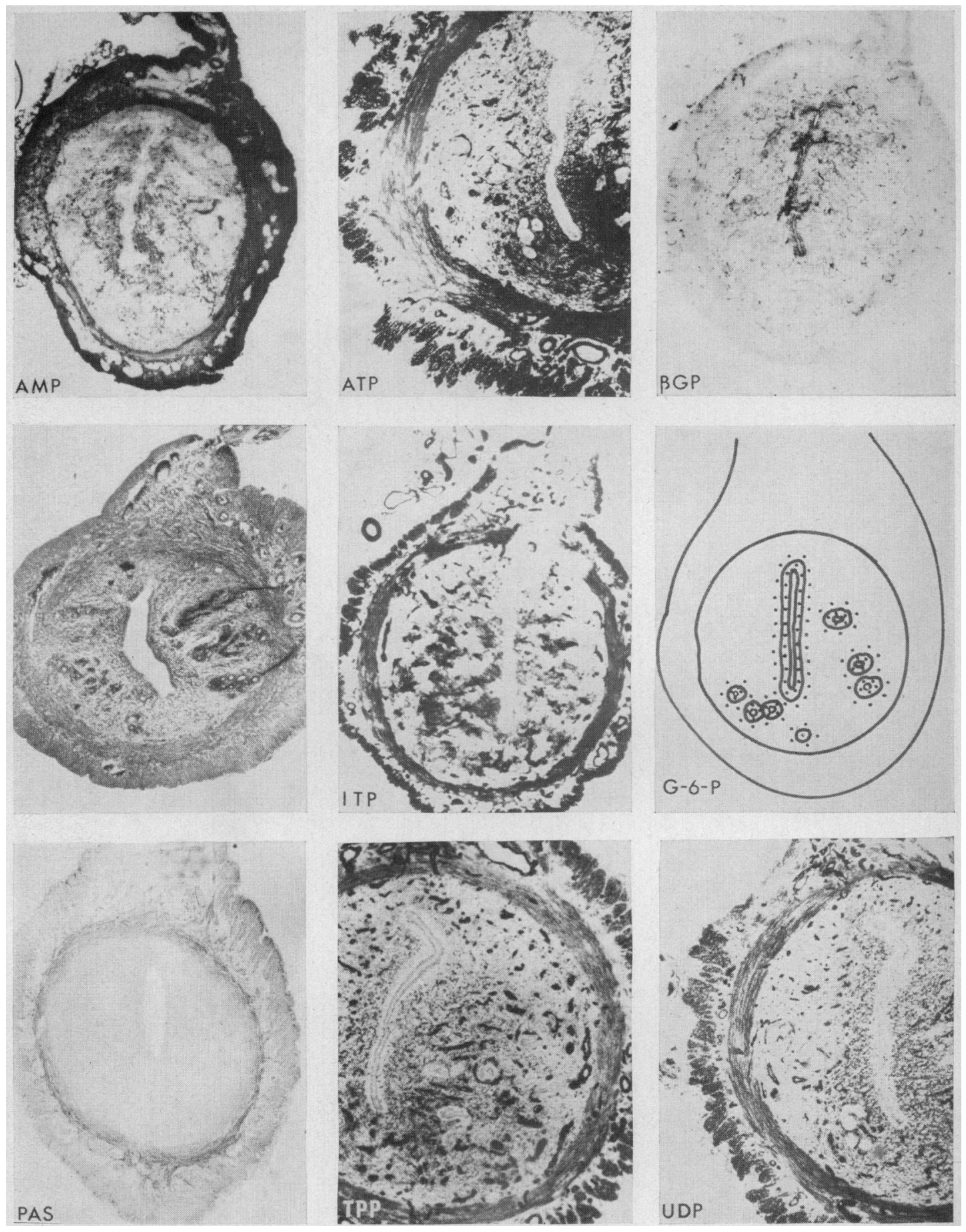

(Facing p. 294) 
PLATE 2
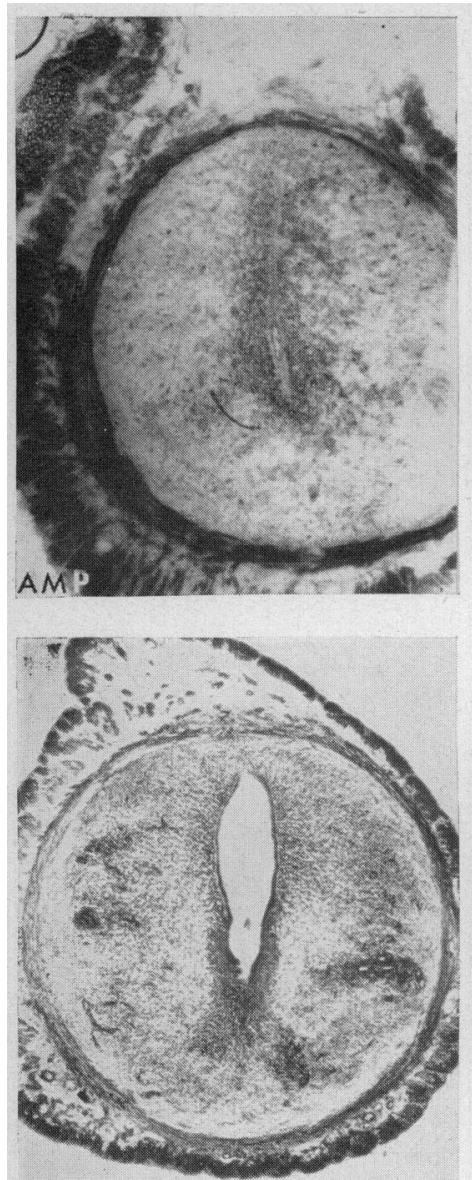

PAS
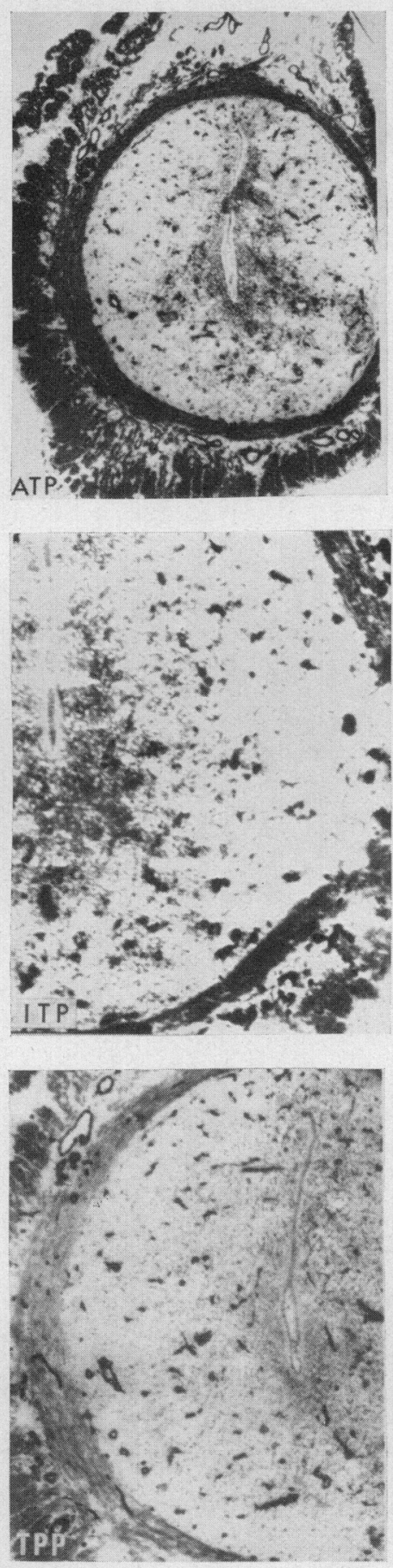
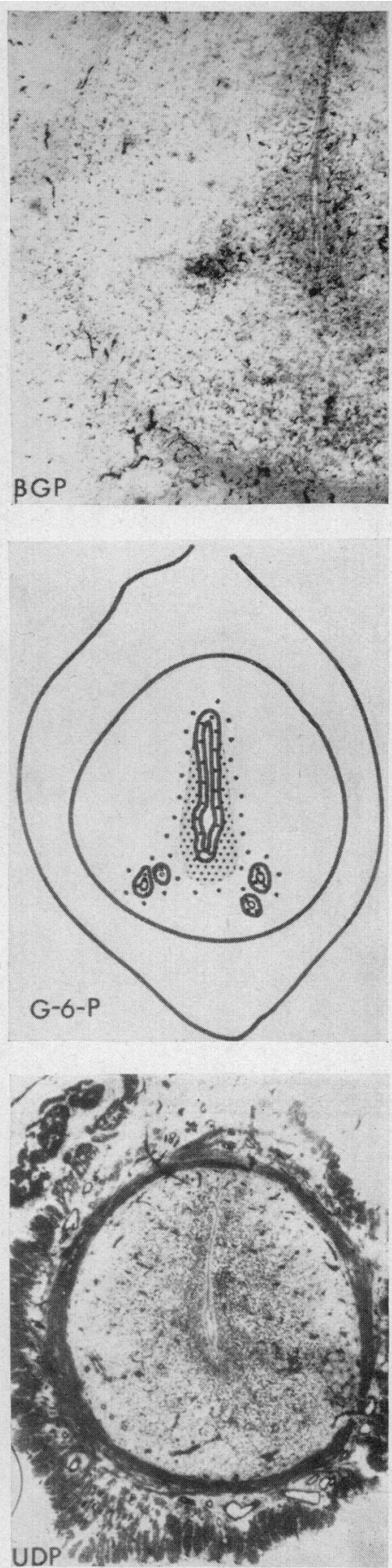
PIATE, 3
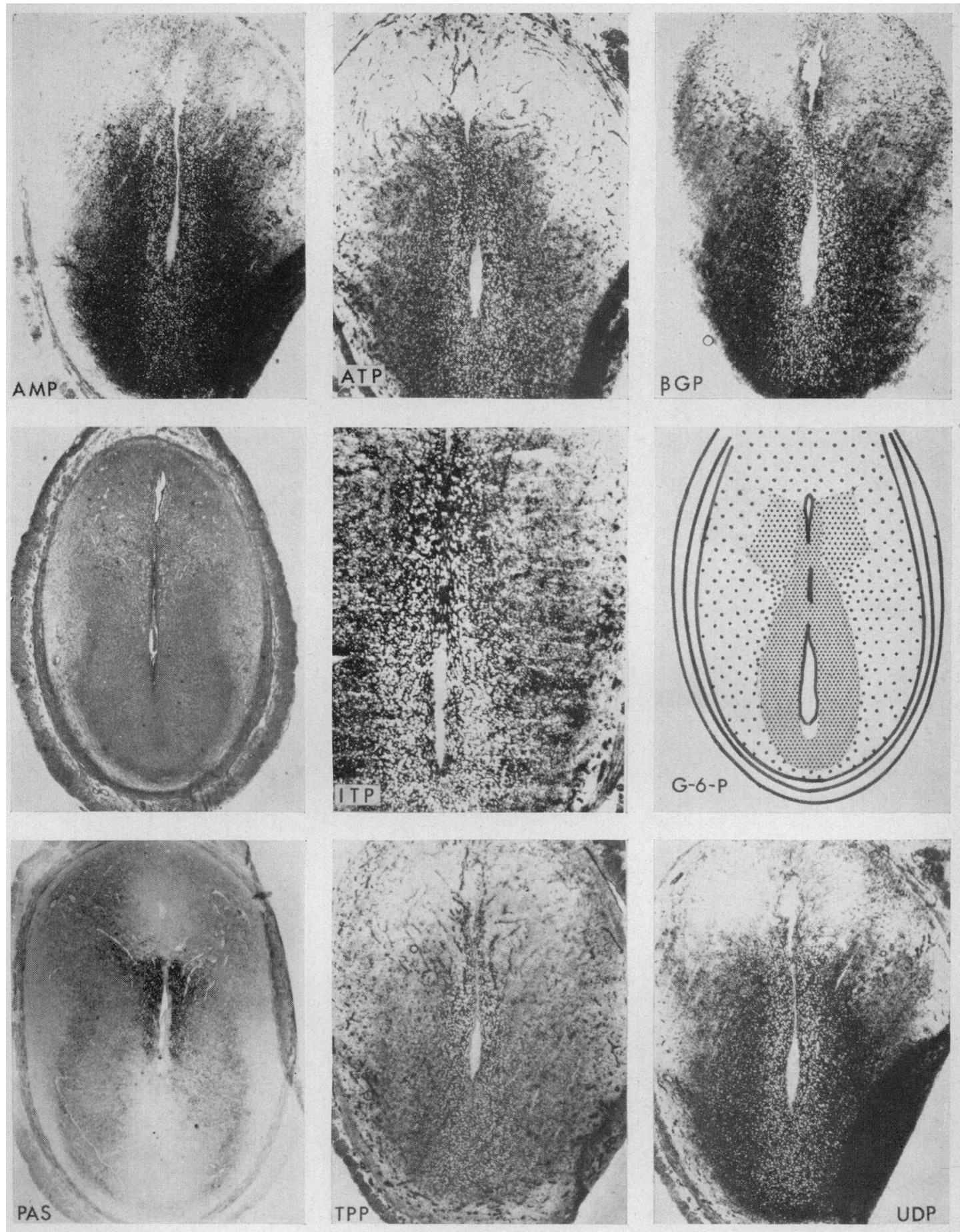
PI.ATE 4
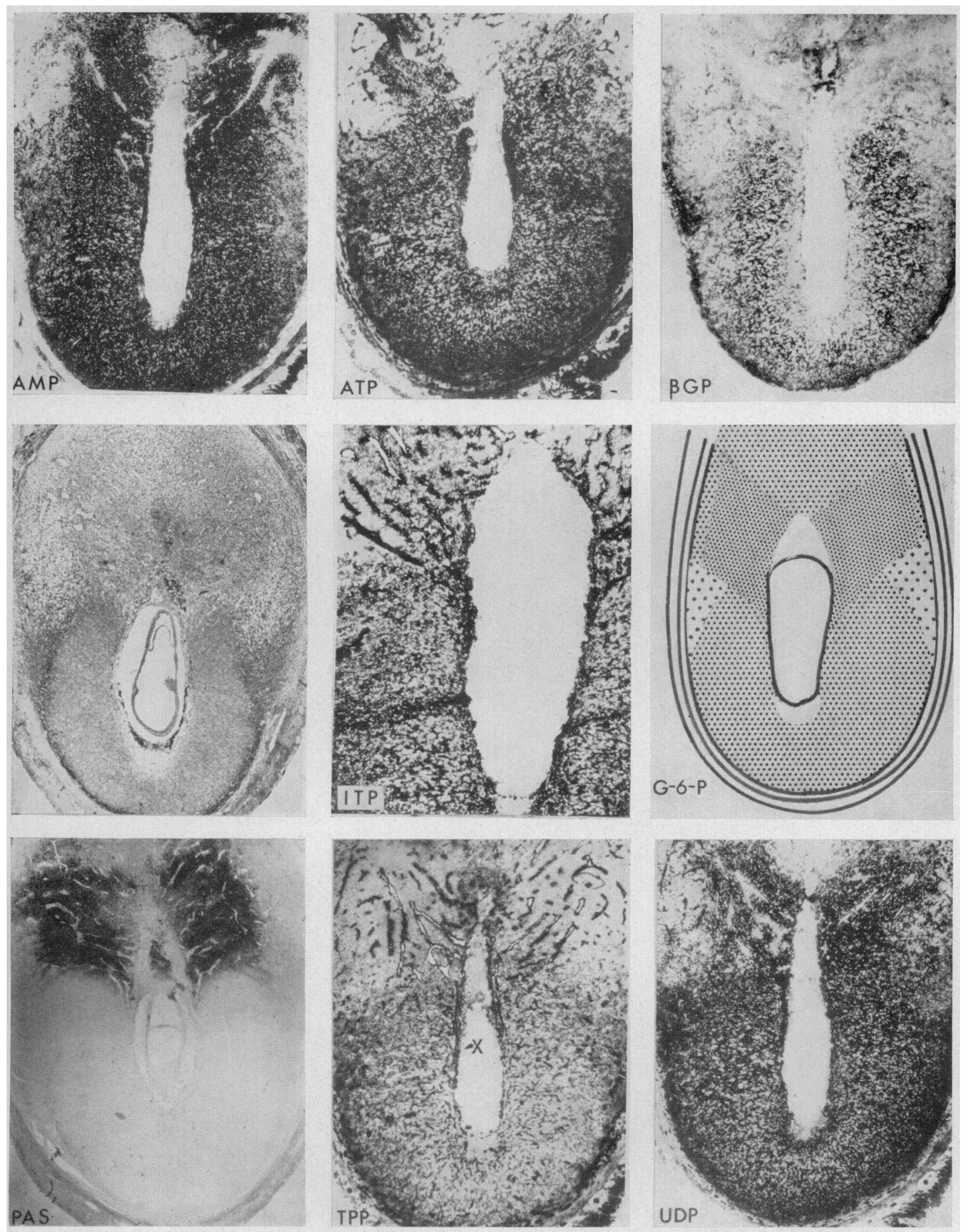